\title{
The Effect of Healthy Nutritional Program on Cognitive and Physical Function Among Fast Food Addict Students
}

\author{
Maaly El-Malky ${ }^{1}$, Nahid El-Gahsh ${ }^{2}$, Samira Abo-Alizm² \\ ${ }^{1}$ Department of Psychiatric Mental Health, Faculty of Nursing, Menoufia University, Shebin El-Kom, Egypt \\ ${ }^{2}$ Department of Medical Surgical Nursing, Faculty of Nursing, Menoufia University, Shebin El-Kom, Egypt
}

Email address:

Malky@yahoo.com (M. El-Malky), Fonadnahid@yahoo.com (N. El-Gahsh), samiraaboalizm@yahoo.com (S. A. Alizm)

\section{To cite this article:}

Maaly El-Malky, Nahid El-Gahsh, Samira Abo Alizm. The Effect of Healthy Nutritional Program on Cognitive and Physical Function Among Fast Food Addict Students. American Journal of Nursing Science. Vol. 4, No. 3, 2015, pp. 94-100. doi: 10.11648/j.ajns.20150403.17

\begin{abstract}
Fast foods are easy available and their delicious taste help students especially the teenagers, get hooked on to it. Fast foods are addictive, and are the silent killer. Aim of the study: Evaluating the effectiveness of healthy nutritional program on cognitive and physical function among fast food addict students. Setting: - Faculty of Nursing Menoufia University. Design: - quiz experimental design (one group pre post test) was utilized. Sample: a purposeful sample of 183 first year female nursing students. Data were collected using structured interviewing questionnaire schedule, it consisted of two parts: Part one: socio demographic data as age, sex, marital status, and education. Part two: assessment of student's knowledge about balanced diet and their state of cognitive and physical function. The collected data were organized, tabulated and statistically analyzed using soft ware statistical computer package version 13. Descriptive statistic for quantitative data using mean and stander deviation while for qualitative data using frequency and percentage for comparison before and after the program using chi-square for qualitative data. Significance adopted at $\mathrm{P}<0.05$ for interpretation of the results of tests of significance. Result: - there were statistical significant improvements of students' knowledge, level of performance, cognitive and physical function also student's perception about dangerous of fast food 3 months post program than pre program. Conclusion:-It is concluded that: the program about healthy nutrition had a positive effect on student's knowledge, cognitive and physical function. Recommendation: - based on this study it was recommended that: special attention should be given regarding teaching students family members about the importance of balanced diet and healthy food to minimize fast food addiction and improve students' cognitive and physical function.
\end{abstract}

Keywords: Cognitive Function, Physical Function, Fast Food

\section{Introduction}

Fast food has become so popular today. It's easy to cook and convenient to eat. The popularity of fast food restaurants increases steadily over time because they're inexpensive, convenient, taste good and serve food quickly. Fast foods are addictive, but not all fast food is bad $[1,2]$. Sometimes, because of their easy availability and their delicious taste, people especially the teenagers get hooked on to it. Fast food is very bad for our health. Some people say fast food is the silent killer because fast food is high in sodium, saturated fat, Tran's fat, and cholesterol, Fast food also lacks many of the nutrients, vitamins, and minerals our bodies need, eating too much over a long period of time can lead to health problems[3].

Fast food restaurants cause many of us to gain weight if we do not know how to control our habit of eating it. If we consume fast food on a regular basis, then it can be hazardous to health. Foods like noodles, wafers, pastries, and pizzas etc. lack nutritious value. They are deficient in vitamins, protein and/or minerals, but rich in sodium and other harmful additives. This leads to diseases like diabetes, obesity, cardiac problems, clogged arteries, reduced bone strength, acidity, liver failure and many other health related problems [4]. Fast food affects the concentration levels in studies and other activities too, it is like a pharmaceutical compound that affects the brain, Diet, exercise and sleep have the potential to alter our brain health and mental function [5]. A balanced diet and regular exercise can protect the brain and ward off mental disorders, In addition to 
helping protect us from heart disease and cancer. This raises the exciting possibility that changes in diet are available strategy for enhancing cognitive abilities, protecting the brain from damage and counteracting the effects of aging [6].

Prevention, early detection and the appropriate treatment of fast food addiction are of great importance in nursing practice in all settings and should not be undervalued. Nurses can promote healthy lifestyle patterns that reduce the risks of fast food among college students through encouraging them to consider the psychosocial and cultural dynamics that affect health behaviors' that lead to obesity [7]. Nurses should participate in health promotion and education for the prevention of obesity and others fast food related problems'. Nurses can promote appropriate nutrition advice not only to the general public, but most importantly to policy-makers. Thus, nurses are on the frontline of obesity prevention and health promotion [8].

Nurse can play a vital role in teaching students the basics of nutrition, including appropriate portion sizes, food preparation, and healthy grocery shopping, is essential. Behavior modification changes, such as keeping unhealthy foods out of the house and modeling appropriate eating and activity behaviors for adult are helpful [9]. So the aim of this study is to evaluate the effectiveness of healthy nutritional program on cognitive and physical function among fast food addict students.

\section{Significance of the Study}

Fast food has become popular today, because of their easy availability and their delicious taste some people especially teenagers liked it. Due to dangerous of it as obesity, heart disease, and the effect of it on cognitive functions among college students and another study in agreement with me [8]. So the aim of this study stand to evaluating the effectiveness of healthy nutritional program on cognitive and physical function among fast food addict students.

\section{Subjects and Methods}

\subsection{The Aim of the Study}

The aim of this study is to evaluate the effect of healthy nutritional program on cognitive and physical function among fast food addictstudents.

\subsection{Research Hypothesis}

Healthy nutritional program will minimize fast food addiction and improve cognitive and physical function among student than before program.

\subsection{Research Design}

A quasi experimental design (one group pre post test) was used to evaluate the effect of healthy nutritional program on cognitive and physical function among fast food addict students.

\subsection{Research Setting}

This study was conducted at Faculty of Nursing Menoufia University on first year students.

\subsection{Subjects}

A purposeful sample of 183 first year female students at Faculty of Nursing Menoufia University who was available during the time of data collection was selected according the following criteria: at first year of study, female student, have regular eating pattern, age (from18 to 20) year, addict fast food, welling to participate on the study, free from history of physical or mental problems.

\subsection{Instruments of the Study}

Structured interview questionnaire schedule was developed by the researcher based on pertinent literature and guidance of expertise including two parts:-

Part one: to assess socio-demographic data as age, sex, marital status, income and education.

Part two: to assess student's knowledge about healthy balanced diet and negative effect of fast food addiction on cognitive and physical function it consisted of (31) questions. Test retest reliability of the tool was done. It was strongly reliable $\mathrm{R}=.92$.

\subsubsection{Reliability of the Tool}

Reliability was applied by the researcher for testing the internal consistency of the tool, by administration of the same tools to the same subjects under similar conditions on one or more occasions. Answers from repeated testing were compared (Test-re-test reliability).

\subsubsection{Validity of the Tools}

They were tested for content validity by jury of five experts in the field of psychiatric and medical nursing staff specialty to ascertain relevance and completeness. The required modification was carried out accordingly.

\subsection{Procedure of Data Collection}

\subsubsection{Preparatory Phase}

Review of relevant literature and different studies related to the topic of research was done to get a clear feature of all aspect of research topic and to design the data collection tools.An official permission was obtained from the Dean of the Faculty of Nursing to carry out the study after the explanation of the aim of the study. Ethical consideration: Protection of human rights was emphasized to the students that the participation in the study was voluntary. Anonymity and confidentiality of the responses was respected. The students had the full right to refuse participate in the study or withdrawal at any time. Before starting data collection a pilot study was carried out on (19) students, to assess the clarity, applicability and time needed to fill the tool. The necessary modifications were done as revealed from the pilot study. The sample of the pilot study was excluded from the total sample. 


\subsubsection{Assessment Phase (Data Collection)}

Data were collected using interview questioner which was developed and tested by the researcher.

\subsubsection{Implementation Phase}

After collection of pre study data (assessment phase) the data obtained were meant to aid in formulating nursing intervention program. Each student was scheduled for minimum of 3 teaching session in three consecutive lectures. Each session lasted thirty minutes for all students. Students received verbal instructions supplemented by written materials as posters of an illustrative guide for more clarifications.

Each student was given health instructions about dangerous of fast food addiction, its effect on physical and psychological function, and encourage them to eating a healthy food with handmade.

The researcher asked the students to repeat knowledge and skills to make a healthy sandwich, to take healthy diet, and make sure that they were successfully mastered.

The other two sessions were done to reinforce the provided knowledge and respond to students questions.

\subsubsection{Evaluation Phase}

All the students enrolled in the program were assessed and monitored two time (pre program and 3 months post program) using the interview questioner schedule which was developed by the researcher and tested for its content validity and reliability and used as a measured tool in this study to evaluate the effectiveness of healthy nutritional program on cognitive and physical function among fast food addict students.

\subsection{Data Processing and Analysis}

The collected data were organized, tabulated and statistically analyzed using soft ware statistical computer package version 13. Descriptive statistic for quantitative data using mean and stander deviation while for qualitative data using frequency and percentage for comparison before and after the program using chi-square for qualitative data. Significance adopted at $\mathrm{P}<0.05$ for interpretation of the results of tests of significance.

\subsection{Limitation of the Study}

There was lack of scientific studies and statistics about magnitude of the problem in Egypt.

\section{Results}

Table (1) revealed that mean age of studied sample was $(18.06 \pm 3.35)$ years. In relation to family income about (54.64\%) had moderate family income and (8\%) of college students had eaten fast.

Table (2) showed that there was highly statistical significance effectiveness in improvement of student's knowledge (post three months of the program than pre program) regarding the dangerous effect of fast food addiction.

Table (3) showed that there was highly statistical significance effectiveness in reducing the number of student's addiction of fast food (post three months of the program than pre program).

Table (4) showed that there is positive significant correlation between family income and the number of eating fast food addiction pre program (i.e. when the income increase the number of eating fast food increase), while post three months of the program there is a negative significant correlation (i.e. the income became constant butthe number of eating fast food decrease) which mean the program is very effective.

Table (5) showed that, there was highly statistically significant effectiveness in improvement of cognitive functions of the students (post program than pre program). Table (6) showed that there was highly statistically significant effectiveness of the program in improvement of college students' performance post program than pre program.

Table (7) showed that, there was highly statistically significant effectiveness of the program on reduction of all physical symptoms post program than preprogram among students.

Table (1). Percentage distribution of socio-demographic characteristics of the studied sample. (Where $N$ refers to number of study subjects and SD refers to standard deviation).

\begin{tabular}{|c|c|c|}
\hline \multirow{2}{*}{$\begin{array}{l}\text { Socio-demographic } \\
\text { Data:- }\end{array}$} & \multicolumn{2}{|c|}{ Participants $(\mathrm{N}=183)$ Pre- Program } \\
\hline & No & $\%$ \\
\hline \multicolumn{3}{|l|}{ Age (years):- } \\
\hline 18- & 0 & 0 \\
\hline $20-$ & 82 & 44.8 \\
\hline$\geq 20$ & 101 & 55.2 \\
\hline Mean \pm SD & $18.06 \pm 3.35$ & \\
\hline \multicolumn{3}{|l|}{ Family Income:- } \\
\hline -Low & 65 & 35.52 \\
\hline -Moderate & 100 & 54.64 \\
\hline -High & 18 & 9.84 \\
\hline \multicolumn{3}{|l|}{$\begin{array}{l}\text {-Number of eating fast } \\
\text { food per day }\end{array}$} \\
\hline 1\day & 89 & 54 \\
\hline $2 \backslash$ day & 53 & 20 \\
\hline$<2 \backslash$ day & 10 & 5 \\
\hline 3-5\day & 6 & 8 \\
\hline$<5 \backslash$ day & 25 & 13 \\
\hline
\end{tabular}


Table (2). Percentage distribution of the effect of the program on the students knowledge about dangers of fast food addiction.

\begin{tabular}{|c|c|c|c|c|c|c|}
\hline \multirow{3}{*}{$\begin{array}{l}\text { Students 'knowledge } \\
\text { Know the dangerous } \\
\text { effect of fast food. }\end{array}$} & \multicolumn{4}{|c|}{ Participants $(\mathrm{N}=183)$} & \multirow{3}{*}{$x^{2}$} & \multirow{3}{*}{ p-value } \\
\hline & \multicolumn{2}{|c|}{ Pre Program } & \multicolumn{2}{|c|}{3 months post program } & & \\
\hline & No & $\%$ & No & $\%$ & & \\
\hline 1 -Yes & 151 & 82.51 & 170 & 90.71 & \multirow{2}{*}{68.6} & \multirow{2}{*}{.000} \\
\hline 2-No & 32 & 17.49 & 13 & 9.29 & & \\
\hline
\end{tabular}

$P=$ test of significance between pre program and immediately post 3 months (where $x 2$ refers to Chi-square test)

Table (3). Percentage distribution of the effect of the program on the number of fast food addiction..

\begin{tabular}{|c|c|c|c|c|c|c|}
\hline \multirow{3}{*}{$\begin{array}{l}\text { Number of fast food addiction } \\
\text { Number of eating } \backslash \text { day } \\
\end{array}$} & \multicolumn{4}{|c|}{ Participants $(\mathrm{N}=183)$} & \multirow{3}{*}{$x^{2}$} & \multirow{3}{*}{ p-value } \\
\hline & \multicolumn{2}{|c|}{ Pre Program } & \multicolumn{2}{|c|}{ 3months post program } & & \\
\hline & No & $\%$ & No & $\%$ & & \\
\hline $1 \backslash$ day & 89 & 54 & 86 & 49 & & \\
\hline $2 \backslash$ day & 53 & 20 & 51 & 33 & & \\
\hline$<2 \backslash$ day & 10 & 5 & 10 & 5 & 274.5 & .000 \\
\hline $3-5 \backslash$ week & 6 & 8 & 16 & 3 & & \\
\hline$<5 \mid$ week & 25 & 13 & 20 & 10 & & \\
\hline
\end{tabular}

$\mathrm{P}=$ test of significance between pre program and immediately post 3 months (where $\mathrm{x} 2$ refers to Chi-square test)

Table (4). Correlation between family income and the number of fast food pre-post program.

\begin{tabular}{|c|c|c|c|c|}
\hline \multirow{5}{*}{ Number of fast food per month } & \multicolumn{4}{|c|}{ Pearson correlation } \\
\hline & \multicolumn{4}{|c|}{ Family income per month } \\
\hline & \multicolumn{2}{|l|}{ Pre Program } & \multicolumn{2}{|c|}{ 3months after program } \\
\hline & $\mathrm{r}$ & P-value & $\mathrm{r}$ & P-value \\
\hline & $.190 * *$ & .000 & $-.023 * *$ & .000 \\
\hline
\end{tabular}

** Correlation is significant at the 0.01 level (2-tailed) "where $r$ refers to Pearson correlation test"

Table (5). Percentage distribution of the effectiveness of the program on students' cognitive function.

\begin{tabular}{|c|c|c|c|c|c|c|}
\hline \multirow{3}{*}{ Cognitive symptoms:- } & \multicolumn{4}{|c|}{ Participants $(\mathrm{N}=183)$} & \multirow{3}{*}{$x^{2}$} & \multirow{3}{*}{ p-value } \\
\hline & \multicolumn{2}{|c|}{ Pre Program(N= 183) } & \multicolumn{2}{|c|}{ 3months post program $(N=183)$} & & \\
\hline & No & $\%$ & No & $\%$ & & \\
\hline \multicolumn{7}{|l|}{ 1-Decrease attention } \\
\hline No & 0 & 0 & 22 & 12 & & \\
\hline All of time & 183 & 100 & 161 & 88 & & \\
\hline \multicolumn{7}{|l|}{ 2- Difficult of recoil:- } \\
\hline Some times & 2 & 1 & 9 & 5 & & \\
\hline All of time & 181 & 99 & 174 & 95 & 274.5 & 0.000 \\
\hline \multicolumn{7}{|c|}{ 3- Difficult of concentration:- } \\
\hline Some times- & 183 & 100 & 2 & 1 & & \\
\hline \multicolumn{7}{|l|}{ 4- Restlessness:- } \\
\hline -No & 0 & 0 & 183 & 100 & & \\
\hline All time & 183 & 100 & 0 & 0 & & \\
\hline
\end{tabular}

$\mathrm{P}=$ test of significance between pre program and immediately post 3 months (where $\mathrm{x} 2$ refers to Chi-square test). 
Table (6). Percentage distribution of the effect of the program on the students level of performance.

\begin{tabular}{|c|c|c|c|c|c|c|}
\hline \multirow{3}{*}{$\begin{array}{l}\text { Students } \\
\text { Performance }\end{array}$} & \multicolumn{4}{|c|}{ Participants $(\mathrm{N}=\mathbf{1 8 3})$} & \multirow{3}{*}{$x^{2}$} & \multirow{3}{*}{ p-value } \\
\hline & \multicolumn{2}{|c|}{ Pre Program(N=183) } & \multicolumn{2}{|c|}{ 3months post program $(\mathrm{N}=183)$} & & \\
\hline & No & $\%$ & No & $\%$ & & \\
\hline Excellent & 51 & 28 & 71 & 38 & \multirow{5}{*}{300.135} & \multirow{5}{*}{.000} \\
\hline Very good & 70 & 38 & 88 & 48 & & \\
\hline Good & 15 & 8 & 3 & 3 & & \\
\hline Pass & 42 & 23 & 16 & 8 & & \\
\hline Failed & 5 & 3 & 5 & 3 & & \\
\hline
\end{tabular}

$\mathrm{P}=$ test of significance between pre program and immediately post 3 months (where $\mathrm{x} 2$ refers to Chi-square test).

Table (7). Percentage distribution of the effectiveness of the program on physical symptoms of the students.

\begin{tabular}{|c|c|c|c|c|c|c|}
\hline \multirow{3}{*}{ Physical symptoms:- } & \multicolumn{4}{|c|}{ Participants (N= 183) } & \multirow{3}{*}{$\mathbf{x}^{2}$} & \multirow{3}{*}{ p-value } \\
\hline & \multicolumn{2}{|c|}{ Pre Program(N= 183) } & \multicolumn{2}{|c|}{ 3months post program $(\mathrm{N}=183)$} & & \\
\hline & No & $\%$ & No & $\%$ & & \\
\hline \multicolumn{7}{|l|}{ 1-Difficulty of sleep:- } \\
\hline No & 0 & 0 & 161 & 12 & & \\
\hline Yes & 183 & 100 & 22 & 88 & & \\
\hline \multicolumn{7}{|l|}{ 2- Hair loss:- } \\
\hline No & 0 & 0 & 183 & 1 & & \\
\hline Yes & 183 & 100 & 0 & 99 & & \\
\hline \multicolumn{7}{|l|}{ 3- Headache;- } \\
\hline No & 0 & 0 & 183 & 1 & & \\
\hline Yes & 183 & 100 & 0 & 99 & & \\
\hline \multicolumn{7}{|l|}{ 4- Nausea and anorexia;- } \\
\hline No & 0 & 0 & 183 & 100 & & \\
\hline Yes & 183 & 100 & 0 & 0 & & \\
\hline \multicolumn{7}{|l|}{ 5- Anemia;- } \\
\hline No & 0 & 0 & 2 & 0 & & \\
\hline Yes & 183 & 100 & 181 & 100 & & \\
\hline \multicolumn{7}{|c|}{ 6- Gastrointestinal disturbances:- } \\
\hline No & 0 & 0 & 161 & 12 & & \\
\hline Yes & 183 & 100 & 22 & 88 & & \\
\hline \multicolumn{7}{|l|}{ 7- Overweight;- } \\
\hline No & 0 & 0 & 183 & 1 & & \\
\hline Yes & 183 & 100 & 0 & 99 & & \\
\hline \multicolumn{7}{|l|}{ 8- Toothache;- } \\
\hline No & 0 & 0 & 183 & 1 & & \\
\hline Yes & 183 & 100 & 0 & 99 & & \\
\hline \multicolumn{7}{|c|}{ 9- Pain of bones and joints:- } \\
\hline No & 0 & 0 & 183 & 100 & & \\
\hline Yes & 183 & 100 & 0 & 0 & & \\
\hline \multicolumn{7}{|l|}{ 10- Blaire vision:- } \\
\hline No & 100 & 0 & 181 & 100 & & \\
\hline Yes & 83 & 100 & 2 & 0 & & \\
\hline
\end{tabular}

$\mathrm{P}=$ test of significance between pre program and immediately post 3 months (where $\mathrm{x} 2$ refers to Chi-square test)

\section{Discussion}

Fast food has become so popular today. It's easy to cook and convenient to eat. Most importantly, it's tasty. Fast food items are slowly replacing our square meals; fast foods were addictive, and are the silent killer [10].The current study managed the effectiveness of healthy nutritional program on cognitive and physical function among fast food addict college nursing students.

Discussion of the results is presented in the following sequence: (a) socio-demographic characteristics of the sample. (b) Assessment of student's knowledge about dangerous of fast food addiction and its effects on their cognitive and physical function. (c) Assess the effectiveness 
of the program on reduction of the number of fast food addiction, physical symptoms, improvement of cognitive function and the level of performances. The results of the present study clarified that, the mean age of the sample $18.06 \pm 3.35$ years. This result is in agreement with [11] who reported that because of fast food were easy in availability and their delicious taste, people especially the teenagers get hooked on to it.

The present study showed that the majority of family income was moderate per month this finding supported by [12] who found that the mean family income was (561 Egyptian pounds). In addition the recent college students, Many have moved out their own and have little money to buy healthy food [13].

The results of the present study showed that highly statistically improvement of the students' knowledge regarding to dangerous effect of fast food addiction post 3 months of the program; this was in agreement with [14] who found in his study that the study compared college students who ate in fast food restaurants less than once each week to students who frequented the establishments more than twice a week.

The present study showed that there was highly statistically significant improvement of cognitive function post program more than preprogram due to decrease the number of eating fast food per week; this was in line with [13] who founded that Fast food affects the concentration levels in studies and other activities too, it is like a pharmaceutical compound that affects the brain. In addition to [15] who mentioned a number of innovative studies point to the possibility that the effects of diet on mental health can be transmitted across generations and lead to decrease of attention and concentration of the students.

The present study showed that there was highly statistically significant reduction of physical symptoms post program more than pre program this could be due to decrease the number of eating fast food per week this was supported by [13] Which founded that, fast food are deficient in vitamins, protein and/or minerals, but rich in sodium, oil, fats and other harmful additives. For someone who consumes these in excess, it may lead to diseases like diabetes, obesity, cardiac problems, clogged arteries, reduced bone strength, acidity, liver failure and many other health related problems.

The current study represented that there was a statistical significance improvement post program than pre program in relation to the level of performance among college students. This was in line with [16] who found that a healthy diet and exercise can improve brain function and lead to better performances.

\section{Conclusion}

The present study revealed that healthy nutritional program increase students' knowledge about the dangerous effect of fast food and improve their performances, their cognitive function and reduce physical symptoms.

\section{Recommendation}

1- Replication of the study using a large probability sample of college students from different geographical areas to allow greater generalizability of the result.

2-Special attention should be given regarding teaching students family members who have an active role in students' nutrition to help them how to eat healthy food and step by step stop fast food addiction.

\section{References}

[1] Krukowski R A, Harvey-Berino J, Kolodinsky J, et al. Consumers may not use or understand calorie labelling in restaurants. J. Am. Diet. Assoc.2006; 106:917-920.

[2] Kim K S andSin S C JS. Perception and selection of information sources by undergraduate students: effects of avoidant style, confidence, and personal control in problemsolving.J.Acad. Libra. 2007; 33(6):655-65.

[3] James WPT, Jackson-Leach R, Mhurchu $\mathrm{CN}$, et al. Overweight and obesity (high body mass index). In Comparative quantification of health risks: global and regional burden of disease attributable to selected major risk factors. Edited by Ezzati M, Lopez AD, Rodgers A, Murray CJL. Geneva. World Health Organization. 2004; 497-596.

[4] Abbasi F, Brown BW, Lamendola C, et al. Relationship Between Obesity, Insulin Resistance, and Coronary Heart Disease Risk.J.Am Coll. Cardi. 2002.2012; 40:937-943.

[5] Morse K L and Driskell JD. Observed sex differences in fastfood consumption and nutrition self-assessments and beliefs of college students.Nutrition Research. 2009; 29:173-9.

[6] Amin TT, Al-Sultan AI, Ali A. Overweight and obesity and their relation to dietary habits and socio-demographic characteristics among male primary school children in AlHassa, Kingdom of Saudi Arabia. Available at Eur. J. Nutr. 2008; 47:310-318.

[7] Anderson R and Fernell. Knowledge, attitudes and label use among college students. J. Am. Diet.Assoc.2011; 107:21302134.

[8] Nguyen NT, Magno CP, Lane KT, et al.Association of Hypertension, Diabetes, Dyslipidemia, and Metabolic Syndrome with Obesity: Findings from the National Health and Nutrition Examination Survey, 1999 to 2004, available atJ. Am. Coll.Surg. 2008, 207:928-934.

[9] Mc Ginnis, D. L.. J. A., J. K. V. O, and Kraak. Food marketing to children and youth: Washington, DC: National Academies Press. 2006.

[10] Franko D L, Cousineau T M, Trant M, et al. Motivation, selfefficacy, physical activity and nutrition in college students: Randomized controlled trial of an internet-based education program. Preventive Medicine. 2008; 47(4): 369-377.

[11] Levi A, Chan K, and PenceD. Real men do not read labels: the effects of masculinity and involvement on college students' food decisions. J.Am. Coll. Heal. (2006)55 (2):9198 .

[12] WHO (2010), Caeneva, Swtzerland: WHO Global Recommendations on physical Activity for health. 
[13] National Institutes of Health/National Heart and Blood Institute (2010): Clinical Guidelines on the identification, evaluation, and treatment of overweight and obesity in adults. Available [http://www.nhlbi.nih.gov/guidelines/obesity/ob_gdlns.pdf]

[14] Lee, H-L. Information structures and undergraduate students.J. Acad.Libra. 2008; 34 (3):211-19.
[15] Nichols J and Mellinger M. Portals for undergraduate subject searching: are they worth it? Libraries and the Academy. 2007; 7 (4): 481-90.

[16] Huffman L andWest D S.Readiness to change sugar sweetened beverage intake among college students. Eating Behaviors.2007; 8(1): 10-4. 